\title{
An interdisciplinary perspective on gamification: Mechanics, psychological mediators and outcomes
}

\author{
Miralem Helmefalk ${ }^{1}$, \\ miralem.helmefalk@1nu.se \\ Abstract
}

As gamification literature has matured, the gap between how different domains apply the theory has widened. This has positioned gamification as being more dependent on context, rather than being an independent theory per se. To address this notion, three concepts are identified as being central for how the designer gamifies a process. These are mechanics, psychological mediators and desired outcomes. Following this logic, a review was conducted using $79(n)$ articles across seven disciplines, namely health and wellness, crowdsourcing, sustainability, computer science, software development, business, and tourism. The findings highlighted potential relationships between several concepts when gamifying a situation, context, service or/and process. This research presents an alternative and uniform perspective on the broad gamification research to better understand how gamification functions and can be employed to impact various outcomes. Furthermore, this research contributes to this rather eclectic domain, presenting a more categorized view in showing domain-specific mechanics and how these can be employed for empirical testing. Lastly, the conceptual model can be modified, employed and adjusted to investigate various effects of gamification on outcomes.

Keywords: Conceptual Model, Gamification, Interdisciplinary, Mechanics, Psychological Mediators, Outcomes;

\section{Introduction}

The last decade has seen a growing trend towards gamification theories beyond the human interaction with computers and across many different research domains [1,2].

The literature portrays gamification as the use of game mechanics in non-game contexts [3], or as Burke [4] defines it, "the use of games mechanics and experience design to digitally engage and motivate people to achieve their goals" (p. 6).

Existing research recognizes gamification as a service or process that can occur in three or more sequential stages [5]. The first stage is the mechanics; decisions, rules and aesthetics for modifying non-game contexts [6]. The second stage is the psychological processes that mediate various relationships $[5,7]$. The final stage is the domain-specific outcome, such as inducing a specific behavior, or other context-specific results [8]. To put these three stages in context [9], whilst the ultimate goal for a marketer is to increase sales, so does gamified marketing (mechanics) need to evoke positive emotions (mediator) in consumers to consecutively motivate purchasing (outcomes) [10]. Consequently, gamified outcomes are highly contextual (domain specific); for example, teachers who want to increase learning outcomes $[11,12]$, or software developers who want to increase productivity [4]. Accordingly, these mechanics should reflect the requirements of the specific context (domain) to be successful. This is also confirmed by Burke [13] who 
pag. 4

discourages applying gamified mechanics without first scrutinizing the fit between individual and organizational goals. Therefore, this notion signifies that mechanics and outcomes are highly dynamic and contextual [14].

In contrast to mechanics and outcomes, the mental processes that lead to these contextual outcomes are portrayed homogeneously in literature [15-18]. Hamari [19] states that "in non-game contexts, game design is increasingly being used to direct people's motivations towards intrinsically motivated, gameful experiences and behavior" (p. 469). Literature portrays these experiences as psychological processes, often in terms of cognitive and emotional states [7]. Needless to say, many different psychological concepts highlight the mediating effects of gamified mechanics as flow, fun that evokes fluency, or simply different aspects of motivation and engagement [17]. Because the impact of these mental states usually aims at impacting different outcomes [9, 15], this research addresses and conceptualizes these mental mediators as gamified psychological mediators (PMs). These should be better understood to provide successful outcomes. Dale [20] emphasizes this notion, "Good gamification design should be user-centric and not mechanism-centric".

Research on the subject has been mostly restricted to limited comparisons of mechanics, dynamics and contextual outcomes, such as physical activity in health or learning outcome in learning [21, 22]. Although research pinpoints these mediators and recognizes them as being important for stimulating outcomes, little has been done to understand which mechanics influence which psychological mediators, and how they proceed to mediate outcomes [23]. In order to fully understand how mechanics impact outcomes, the link between mechanics, psychological intermediaries and outcomes, needs to be better understood, described and categorized in relation to the effects [10]. Gamification, being multidisciplinary, faces a major obstacle in establishing itself as a discipline. As gamification is eclectic in nature [24], the theory needs to be better categorized and explored in order provide arguments for empirical inquiry. Developing and conceptualizing this would provide a clearer picture of how to measure gamification across the different domains and to strengthen the theory, which, as Nacke and Deterding [25] state, is just beginning to mature. Thus, the purpose of this review is to develop a conceptual model unifying gamification literature across different domains to guide further research in understanding the process of mechanics, psychological mediators and contextual outcomes. The research question is: How does gamification literature portray the effects of mechanics, psychological mediators and outcomes?

Additionally, understanding how psychological mediators' function across several domains when being impacted by mechanics would strengthen the concept of gamification as a theory and synthesize the already eclectic nature of gamification theory, especially in how people interact with computer-based services. Due to the importance of mechanics, psychological mediators and outcomes in gamification research, the purpose of the research is to review, clarify and synthesize these concepts together in the multi-disciplinary domain of gamification. To contribute to gamification as a general theory this research addresses this scarcity in literature by reviewing gamification in seven different domains and then discussing the literature to develop a conceptual model showing the relationships between mechanics, psychological mediators and outcomes. The remainder of the paper presents a short description of the employed theoretical concepts, such as gamification, mechanics, psychological mediators, outcomes and describes how the review was conducted (section 2 ). The findings are then discussed (section 3 ) and a conceptual model developed (section 4). Lastly, conclusions, limitation and future research are presented (section 5). 


\section{Mechanics, psychological mediators and outcomes}

Gamification is described as using game thinking and its fundamental mechanics in nongame contexts [26, 27]. Its central feature is to motivate and engage people in conducting desired behaviors. Nacke and Deterding [25] emphasize that gamification has grown from a novel research topic into a thriving multidisciplinary field and this is evident in the excessive number of domains that investigate the effects of gamification. According to O'Donnell et al. [24], the most common domains that apply gamification to examine outcomes are health and wellness, crowdsourcing, sustainability, computer science, software development, marketing (services, servicescapes, customer engagement) and tourism [28, 29]. Interestingly, gamification is highly multidisciplinary [23], which reflects the variations of disciplines that have applied it as a theory. Being widely used in different disciplines, it also raises the question of whether gamification is becoming a co-dependent theory by being dependent on the existence of different contexts, such as the concept of advertising is dependent on different technologies (radio, TV). Likewise, gamification has become dispersed in literature with a multitude of variations and perspectives, which leaves the theory rather eclectic.

Many of the conducted reviews have categorized the mental states influenced by game mechanics in categories sorted by a common denominator, such as sorting different psychological mediators under motivation or engagement. To reveal the actual mental processes, such as motivation or emotions, this review examined the existing literature in order to gain a more refined perspective on the matter.

While some literature, such as Dichev and Dicheva [7] treat all cognitive, affective and behavioral elements as an outcome of gamification, Hervas et al. [30] instead state that there is still a need to know which mechanics trigger which psychological concepts that subsequently impact behavioral changes. The scarcity of this knowledge consequently leaves gamification research putting more emphasis on the mechanics and outputs than to understand for how these mechanics are influencing outcomes, such as learning, economic or other, with individuals' cognition and emotion. On one hand, Johnson et al. [31] confirm this by stating that behavioral outcomes are most researched among cognition, emption and behavior. On the other hand, Alahäivälä and Oinas-Kukkonen [32] state "There is not yet a clear, generally accepted vision of the relationships among the contextual factors, gamification strategies, and study outcomes." (pp. 69). Thus, there seems to be a consensus in literature that questions the linkages between the mechanics as being unclear and in need for future research [33]. Interestingly, Sailer et al. [23] show that gamified mechanics does not automatically influence motivation, but that specific mechanics influence specific psychological outcomes. Needless to say, knowing exactly which mechanics impact on which psychological mediators is still in debate and requires further years of empirical inquiry.

The review is based on a comprehensive literature study, which categorizes research on gamification, and investigates the effects on mechanics, psychological outcomes and various outcomes. In this regard, studies from different domains have been investigated. According to Gall et al. [34], Hart [35] and Randolph [36], literature reviews have several different potential purposes, where the purpose of this review is to develop a conceptual model unifying gamification literature across different domains. To address this, the study produces a comprehensive list of literature, categorized in tables that are based on predefined criteria [37]. A qualitative literature review is then conducted, as described in Randolph [36].

Following the theoretical framework of Hamari et al. [5] and Helmefalk and Marcusson [10], current theory is organized according to mechanics, psychological mediators and outcomes (figure 1). Dichev and Dicheva [7] conducted a literature review, examining literature that includes mechanics and affective, cognitive and behavioral outcomes. This study recognizes behavioral outcomes as a final outcome, mediated by the 
pag. 6

cognition and/or emotion. Note that an outcome may also consist of cognitive and affective traits. To review suitable research in health and wellness, crowdsourcing, sustainability, computer science, software development, marketing (services, servicescapes, customer engagement) and tourism, the sources were extracted from several systematic literature reviews $[1,17,38,39]$ and by retrieving literature from databases, such as Google Scholar and Scopus.

For the data gathering procedure for reviews as suggested by Randolph [36] and Dwan et al. [37], the employed criteria required all research to include gamified mechanics, an outcome and a mental construct that conceptually, argumentatively or empirically mediates the relationship between mechanics and outcomes. As seven large domains were included that included gamification, many different keywords were used to identify gamification in research: gamification, gamified, games, mechanics, serious games and dynamics. A total of 240 (n) articles and conference proceedings were found, after carefully reading and categorizing research in tables, showing which mechanic impacts on which mediator and on what outcome. The studies that fit the criteria were 79 (n).

Studies that included mechanics, psychological mediators and outcomes, were reread, then analyzed and structured according to a M-PM-O table. 79 (n) Articles and conference proceedings were found, of which 18 (n) are in business and marketing, 14 (n) in crowdsourcing, 12 (n) in learning, $10(\mathrm{n})$ in computer science, 8 (n) in sustainability research, 5 (n) in tourism and 12 (n) in health and wellness. These were then read and conceptually discussed. To address the purpose of this review, the identified mechanics and psychological mediators were structured according to the domain, while identifying common denominators in order to categorize the findings.

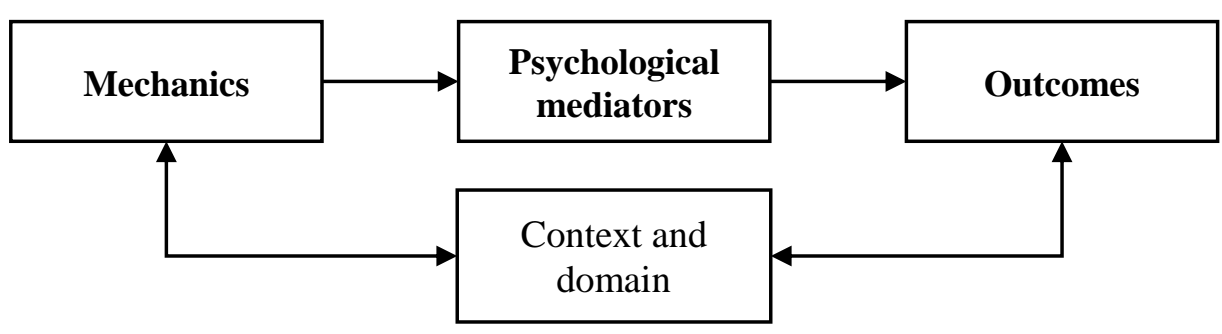

Figure 1. The theoretical framework of M-PM-O processes in a gamification con 
Table 1. Mechanics, Psychological mediators and Outcomes

\begin{tabular}{l}
\hline Authors and Context \\
\hline Business/Marketing \\
Bittner and Schipper [40], Cochoy and \\
Hagberg [8], Conaway and Garay [41], \\
Dymek [42], Hamari [43], Harwood and \\
Garry [14], Hofacker et al. [33], Holzwarth \\
et al. [44], [45], Huotari and Hamari [46], \\
Insley and Nunan [47], Lucassen and Jansen \\
[48], Müller-Stewens et al. [49], Robson et \\
al. [50], Rodrigues et al. [51], Witt et al. \\
[52], [53]
\end{tabular}

\section{Crowdsourcing}

Altmeyer et al. [54], Bowser et al. [55],

Eickhoff et al. [56], Feng et al. [57], Itoko et

al. [58], Kawajiri et al. [59], Kobayashi et al.

[60], Morschheuser et al. [17], Preist et al.

[61], Prestopnik and Tang [62], Roengsamut

et al. [63], Snijders et al. [64], Tinati et al.

[65], Zeng et al. [66],

\section{Learning}

Arnab et al. [67], Bonde et al. [68] Carvalho et al. [69], Hakulinen et al. [70], Hanus and Fox [22], Hasegawa et al. [71], Holman et al. [72], Krause et al. [73], Lehtonen et al. [74], Nevin et al. [75], Pedro et al. [76], Pettit et al. [11], Su and Cheng [12]

\section{Mechanics}

Gamified slogans, Earning, Gaining, Progress, Feedback, Reward, Interface, User experience, Geo-location, Mapplotting, Challenge, Tasks, Badges, Leaderboards, Win condition, Story, Aesthetics, Avatars, Rules, Conflicting goals, Uncertain outcomes, Games, Pricing, Competition, Social, Restrictions, Playfulness, Points, Activity counter, Sport cues

Points, Leaderboards, Badges, Levels, Personal profile, Reputation, Games,

Location based mechanics, Social,

Progress, Pattern recognition, Feedback, Ranking, Score, Winning, Play, Puzzle, Challenge, Competition, Interface, Story, Rewards, Fantasy, Roles, Exploration, Groups, Resources, Endorsements, Virtual territory,

3D, Story, Avatar, Scoring, Badges, Rewards, Ranking, Results, Points, Levels Leaderboard, Cooperation, Game, Game Interface, Boss, Pathways, Exploration, Goals, Achievements, Social,

Announcements, Participation,

Competition, Feedback, Team, Challenge,

\section{Psychological mediators}

Flow, Attitude, Enjoyment,

Addiction, Engagement,

Participation, Relationship

Reward, Competition, Fun, Active participation, Social comparison,

Clear goals, Trust, Commitment,

nvolvement, Credibility,

Likeliness, Curiosity, Involvement, Usefulness, Intrinsic motivation,

Perceived enjoyment,

Hedonic/Utilitarian Value,

Perception of usefulness,

Intrinsic motivation, Attitudes, Fun Enjoyment, Engagement,

immersion, rewarding,

Involvement, Encouragement,

Incentive reinforcement, Social

motivation, Relatedness,

Autonomy, Mastery, Purpose,

Contribution, Interesting, Learning,

Self-learning, Social-belonging, goals, immersion, flow, Social influence, Recognition, curiosity,

Self-presentation, Self-efficacy, Playfulness

Intrinsic Motivation, Immersion, Fun, growth, Engagement, Socia engagement, Acceptance,

motivation, purposefulness, The Intrinsic Motivation Inventory

(IMI), interest/enjoyment,

perceived competence, perceived

\section{Outcomes}

Purchase intention, Purchase behavior, Re-purchase intentions, Increased sales, Satisfaction,

Relationships, User activity, Exchange, Loyalty, Retention, Value, Suspense, Shopping experience, Awareness, Consumer adaption, Use behavior, Idea generation, Brand attitude, Brand love, WOM,

Quantitative/Qualitative contribution, Long term engagement, Solving tasks Contribution and involvement, App use, Efficiency, Quality,

Proofreading, Work time,

Behaviors, Worker performances, Data collection, Played rounds,

Knowledge base contribution, Perception on working task, Commenting, Branching, Voting, Task complexity, Participation

Learning outcomes, Submission time, Attempts, Early submission, Accuracy, recall precision, Logins, Page views, Grade, Retention period, Test performance, Quiz accuracy, Total time, Number of exercises, Solving, Participation, 


\section{Computer science}

Ašeriškis and Damaševičius [77],

Carmosino et al. [78], de Melo et al. [79],

Dencheva et al. [80], Fernandes et al. [81],

Foucault et al. [82], Foucault et al. [82],

Snipes et al. [83], Sukale and Pfaff [84],

Thom et al. [85]

\section{Sustainability}

Gamberini et al. [86], Geelen et al. [87],

Gustafsson et al. [88], Knol and De Vries

[89], Morganti et al. [90], Salvador et al.

[91], Senbel et al. [92], Stone et al. [93]

\section{Tourism}

Egger and Bulencea [94], Sever et al. [95], Sigala [96], Xu et al. [97], Xu et al. [98],

\section{Health}

Ahtinen et al. [99], Allam et al. [21], Chen and $\mathrm{Pu}$ [100], Fleming et al. [101], Hamari and Koivisto [102], Johnson et al. [31],

Kadomura et al. [103], Kuramoto et al.

[104], Riva et al. [105], Thorsteinsen et al.

[106], Tracy and Laura [107], Whittinghill

[108],
Progress, Status, Prizes, Chance, Surprise, Anticipation, Humor, Ownerships, Rules, Location Based, Completion, Movement, Manipulation

Rewards, Leaderboards, Feedback, Rules, Levels, Ranking, Social, points, scores, dashboard, Avatars, Experience, Game,

Badges, Audio-Visual artifacts,

Feedback, Tips, Challenges, Social sharing, Rewards, Rankings, Levels, Points, Competition, Goals,

Explore, Challenge, achievement, Fantasy, Levels, Points, Rewards, Progress,

Leaderboards, Relatedness, Badges, Competition, Rating, Gifting, Social, Location, Sharing, Clear goals, Fun,

Collaboration,

Achievement, exploration, Rewards,

Virtual artifacts, Progress(paths), Points,

Badges, Medals, Leaderboard, Backstory.

Avatar, Social, Competition, Feedback,

Levels, Level-up system, Audio,

Challenge, Goals, choice, pressure/tension, Learning motivation, Learner empowermen

\section{Engagement, Interesting,}

Comprehensible, Relevance, Fun, Interesting, Playfulness, Intrinsic motivation, Incentives,

Engagement, Fun, intrinsic motivation, Challenging, Moral, Knowledge, Responsibility, awareness, Commitment, peer pressure, Concerns for environment, incentives, Socia motivation, Motivation,

\section{Social, Fun, Motivation,}

Immersion, relatedness, autonomy,

competence, Flow, Task

engagement, enjoyment,

Engagement, Motivation,

Relationships, Accomplishment,

Positive emotions, Meaning

Engagement, immersion, Low effort, Motivation, Fun, Social interaction, incentive, Peer

pressure, recognition,

Companionship, Affect, mood,

"Work out for likes", Recognition, reciprocity, Social influence, Focus, Novelty, Empowerment, Autonomy, affect
Knowledge, Interactions, Points, Learning achievement, Final exam score

Performance, Collaboration, Reviewing, Rating, Readability, Participation, Involvement,

Learning, Testing, Reporting, Navigation, Points, Usability, Writing, Reading, User activity, Development time

Acceptance, Usability, Activities, Saving behavior, Attitudes, Change in behavior, Intention to engage, awareness,

Play games, Visit, Check-ins, registrations, Awareness,

Behavioral outcomes, Decision making, Experiences, Brand awareness, Enhance experience, Customer loyalty,

Relieve stress, Wellbeing, Prevent depression, SWTL, Wellness, Physical activity, Healthcare utilization, Use of medication, Website usage, Drinking behavior, Mental health, System use,

Improved food consumption, Pain burden, 


\section{Conceptual discussion}

\subsection{Mechanics}

The following section discusses the literature drawn from the theoretical framework (figure 1) and conceptualizes the found linkages. Prior to discussing the variety of mechanics in literature, there are some mechanics that are considered to be the ground stones of gamification. These are points, badges and leaderboards, and are in the majority of studies used as a starting point for inquiring into the effects on users [19, 109]. However, as table 1 and table 2 show, there is a variety of different mechanics. It becomes therefore difficult to determine causal inferences. For instance, gifting can be seen as a part of a social mechanism, but also as a mechanism for rewarding the user.

In table 2, denominators were analyzed and chosen in relation to the proximity of other concepts, in order to be recognizable and in line with the common discourse in research. These denominators show the variety of concepts that occur in literature. Regardless of which concepts are chosen within a denominator, these can be used to understand gamification mechanics from an interdisciplinary perspective.

Table 2. Mechanics in gamification

\section{Common Mechanics}

Achievements, Badges, Gaining/Earning, Rewards, Stamps, Tokens,

Unlockable content, Virtual objects (currency/goods),

Competence, Merit, Skill-development,

Skill-

Competence, Merit, Skill-development,

development

Leaderboards, Performance graphs, Ranking,

Leaderboards

Clear goals, Competition, Conflicting goals, Restrictions, Rules, Time-

pressure, Uncertain outcomes, Win condition,

Goals/Rules

Betting/Gambling, Challenges, Levels, Mini-games, Mission/Quests, Pattern Mission/Quests recognition, Progress, Riddles, Trials,

Activity counter, Life, Points,

Points

Autonomy, Avatars, Character, Customization, Roles, Self-expression, User profiles,

Collaboration, Gifting, Sharing, Social+concept, Status, Teams, Voting,

Social mechanics

Dashboard, Gamified slogans, Interface, Virtual territories, Visual-metaphor Aesthetics /Aesthetics,

Economy/Marketplace, Feedback, Location based mechanics, Storytelling,

Other User-generated content, Escape, Fantasy, Fun, Playfulness, Recreation, Movement

Rather than listing and discussing all mechanics and denominators, the most common ones $[1,17,38,39]$ will be discussed for the purpose of this review. 
pag. 10

\subsubsection{Mechanics as a tool}

The review lists badges as a common and an important tool for recognizing achievement within the rules of service, practice or offering [70]. While badges, rewards, virtual stamps or tokens can act as an incentive (prior-behavior), they also function as a confirming reward to generate certain desired behaviors (post-behavior). Thus, it becomes a loop, inducing certain psychological mediators and behaviors. While badges and related concepts can also be a social component the different mechanics undoubtedly influence each other on many various levels. Whereas points, sometimes illustrated as "life bar" or "counter", can either be an indicator for how many chances are left or be an indicator for points which later are illustrated in leaderboards that subsequently act as a social mechanic and so on.

A study by Carvalho et al. [69] did in a comprehensive study identify various elements and mechanics and conceptualized an model called, activity theory-based model of serious games that can aid in structuring and understanding serious games. Their study summarized action tools goals into various different mechanics that can be used in learning context, as well as in others.

While skill-development may be discussed from the perspective of psychology, in terms of mechanics it comprises ways of providing tools and channels that allow people to advance, either symbolically, for instance, through a virtual territory [66], a character [68], a certain skill, or through personal growth and relevant knowledge in sustainability [90]. Through this growth a player can boast and be rewarded socially with recognition, through leaderboards [109]. While it can be ambiguous for players/people whether or not they have achieved progress or knowledge, ranking may be a solution, which per se aesthetically and visually juxtaposes progress and reward by presenting added options, such as unlocking new courses [110], or giving the player previously unauthorized access. It seems that there are underlying reward mechanisms in terms of control and power within the rules of the "non-game". This seems to replace the extrinsic rewards that usually comprise monetary rewards or other desired resources [2]. By involving these various mechanics, the player can undertake identities and roles which involve the person in solving missions, goals, quests and other analogous concepts.

In regard to the discussion above, it may not be so far-fetched to exemplify academic research as being cleverly gamified; positions and titles as ranking, skill development as knowledge, leaderboards and points as citations and publications.

It is important to understand the desired outcomes of applying certain mechanics and that applying mechanics can be "reverse engineered" by really understanding what outcomes are desired. For an institution as a university, the output can be research output, but for a smaller business the outcome can be customer loyalty or increased sales [14]. It becomes, thus a question of identifying the desired outcome(s).

Although these mechanics can be seen as a tool, instrument or a means of evoking certain behaviors, these are predominantly implemented digitally. Despite this review and other systematic reviews in different domains $[2,7,39,111]$, there is still an uncertainty in how to best employ mechanics, especially in learning contexts [7]. However, research also shows the potency of gamification and that implementing it is more complex than many practitioners initially believe [13].

Although many studies investigate one or more mechanics and their subsequent impact on users, in terms of the discussion above, there is no doubt that the interplay between different mechanics and their subsequent mediating effects are complex. Thus, it becomes a question of how adding congruent mechanics moderate the effect on users. For instance, does the effect become half, twice or three times stronger, when adding an additional mechanic?

\subsubsection{Common, Shared and Unique}

The mechanics are infused in various offerings and services, tailored for each occasion. As there is a considerable amount of literature (table 1) explaining the different game mechanics and their subsequent role for each domain, there are more or less common 
mechanics that are shared among the different domains. The literature indicates that mechanics tend to be separated in different 'levels'. As previously mentioned, badges, leaderboards and points are frequently mentioned in the context of gamification, sometimes to the degree of misleading practitioners into believing that simply applying these will guarantee success [13]. With regard to how domain-specific some mechanics are, such as learning outcomes in the domain of learning $[11,12,76]$, or drinking behavior and health in the domain of health $[39,101]$, mechanics likewise roughly represent the domains. The review shows that some mechanics are more or less shared and used in literature, while others are context-specific.

It can be speculated that these unique mechanics could contemporarily indicate that they fit within the domain. Despite their uniqueness, all mechanics are context-specific, meaning that a badge is tailored to the service or process in question. Hence, each health context should be unique per se.

\subsection{Psychological mediators}

Many of the identified psychological mediators (table 3) are polysemantic and are to some degree synonymous with each other. The semantic linkages between these are more or less obvious. For instance, purpose and motivation can be related, but simultaneously refer to distinctive conditions, such as a feeling of purpose can motivate, or motivation can impact the perception of purpose. In many cases the semantic use of some theories is chosen in relation to previous literature, and thus become intertwined and vague in terms of categorizing them for further empirical measurement. Thus, it becomes a discussion of semantic congruence and how well a concept fits within a context. In order to sort literature in a more general and comprehensible manner, psychological mediators are categorized in common semantic concepts to illustrate a more general view of how individuals are affected by gamification.

Table 3. Psychological mediators in gamification

\begin{tabular}{l}
\hline Common mediators \\
\hline Social comparison, Social motivation, Social interaction, Social \\
influence, Companionship, Social engagement, Social-belonging, \\
Relationships, Peer pressure, "Work out for likes", Recognition, \\
Self-presentation, Reciprocity,
\end{tabular}

Affect, Mood, Positive emotions, Fun, Enjoyment, Playfulness,

Affect

Incentive reinforcement, Incentives, Rewarding, Intrinsic motivation, Encouragement, Motivation, Learning motivation, Pressure/tension,

Flow, Engagement, Interesting, Challenging, Immersion, Task engagement, Focus, Mastery, Involvement, Curiosity,

Denominator

Social

Goals, Purposefulness, Purpose, Contribution, Relevance,

Accomplishment, Growth, Usefulness, Responsibility, Meaning,

Attitude, Comprehensible, Low effort, Addiction, Relatedness,

Commitment, Moral, Perceived value, Acceptance, Novelty,

Incentive reinforcement/ motivation

Engaging/ cognitive stimulating

Purpose, meaning, fulfillment

Other cognitive

Autonomy, Perceived choice, Empowerment, Trust, self-efficacy

Autonomy/ the sense of control

Awareness, competence, Concerns for environment, Knowledge, Knowledge Learning, Self-learning, Credibility, 
pag. 12

Some of these central concepts will be elaborated and discussed since they are frequently used in literature.

\subsubsection{Intrinsic motivation / Incentives}

Motivations, more specifically intrinsic motivation, refer to the inner desires and facilitators for exerting certain behaviors [15]. While external motivators can include elements of perceived value or punishment, intrinsic motivators are those that in psychology are explained as being internal and include the need for autonomy, competence, and relatedness [31]. These motivators are also discussed as impacting other psychosomatic elements, such as the cognitive need, self-efficacy and others [57]. In literature, it is difficult to demonstrate exactly the linkages and the causative pathways between mechanics, mediators and outcomes [30, 31]. To illustrate this, a mechanic, designed as a badge or a reward, has been shown to impact intrinsic motivation to perform certain tasks [60]. However, exactly which psychological concepts or mediators contribute most impact and how they relate to each other remain unanswered. Feng et al. [57] recent study contributed to this discussion by showing several sub-constructs of intrinsic motivation and which mechanics influenced which sub-constructs that mediated participation. Thus, gamification literature is less concerned with multiple mediation than single mediation. For instance, a mechanic (badge, points) influences a psychological mediator (incentive) that mediates other mediators (intrinsic motivation). In business and marketing, research shows that intrinsic motivation is influenced by idea generation and purchase intention [40, 52]. Crowdsourcing as a domain uses intrinsic motivation in several studies, influencing participation, contribution, and worker performance $[56,60,63,66]$. Other domains that emphasize the effects of motivation are learning [76], computer science [77], sustainability [88], tourism [94], and health [31]. The variety of using motivation as a prerequisite for other constructs is maybe rational as the semantic meaning by itself indicates a followed action.

\subsubsection{Engagement/Flow}

In table 3, it is evident that engagement is a significant factor and is widely discussed as an important variable [2]. Literature shows that one of the main goals of gamification is to achieve mental engagement [15]. Characteristics such as flow, engagement, interest, challenge, immersion, task engagement, focus, mastery, involvement and curiosity are at least semantically and theoretically distinctive. All of these tend to consider the response to stimuli. As such, the concept of flow has become widespread, encompassing several constructs in table 3. Flow is a term originating in psychology to define a conscious state which occurs when a person is immersed within an activity $[40,112]$. Flow is also described as a form of task involvement, enjoyment, and focus that individuals experience in an activity. With regard to gamification research, Harwood and Garry [14] state:

"[...] a key component of gamification, which arises out of comprehension and experiential mastery of the challenges within a particular environment and the accompanying emotional, i.e. positive sensation of competence, through endeavour and labour that this engenders.” (p.535)

As underlined by Harwood and Garry [14], flow impacts cognition and emotion, such as the level of engagement. Thus, flow becomes an important determinant for motivational outcomes which per se mediate various behaviors and contextual outcomes. In research the concept of flow is widely used and has become a central part of gamification literature. Numerous gamification studies have argued, discussed and investigated the impact of mechanics on flow $[14,40,46,52,62]$. 


\subsubsection{Social}

Considerable gamification literature concerns the social aspects of gamification and many different variations of it (see table 1 and 3), even to the extent of explaining the social part in terms of planned behavior [5]. Despite the widespread explanation of social mechanism being a central part of gamification, few actually explain the psychological processes or theories around it, expecting them to be a motivating factor [17]. Several studies emphasize that gamification impacts the social interaction between people and that one's desire to belong or gain recognition from others acts as a strong predictor for conducting certain tasks [90, 102]. For instance, Hamari [43] study shows that badges can impact on social comparison and this subsequently mediates user activity. Other studies show instead how social motivation and a sense of community influence data collection in the context of crowdsourcing $[61,65]$. It is evident in the review that the specific domains and context sometimes regulate the use of social components as psychological mediators. For instance, crowdsourcing, that generally involves many different individuals in solving a particular tasks, is more likely to involve social encouragement and motivation to recognize the involvement of participants [17]. Extrinsic motivators, such as money function in certain jobs, actions or performances whereas social credits are equally important in other contexts [73].

In contrast to other mediators, the social element has a dual property in acting sometimes as a gamification mechanic, and in other situations functions as a psychological mediator. For example, 'social' (e.g. points//leaderboards) as a mechanic can constitute modifying a service in order to stimulate social activity. 'Social' as a mediator comprises various mental processes that mediate other psychological outcomes or behaviors. Despite being a central feature and concept in gamification, it is still largely underdeveloped, especially with regard to how these factors influence each other.

\subsubsection{Affect}

Affect is in psychology referred to as a central concept comprising emotion, mood, and attitude [113]. Affect generally describes whether a state or perception of something is positive or negative [114], and branches out to other concepts, such as emotion, mood and attitude, which portray their own facets. Mood is not as predictive and is more difficult to influence with external stimuli [115]. While being hard to directly influence, it has strong moderating properties on other relationships. Contrastingly, attitude is instead defined as both the cognitive mental process, [116] and as emotional mechanisms [113]. Emotions on the other hand, include the component arousal [114] and occurs in briefer moments than mood. Emotions have an impact on bodily and behavioral reactions, for instance blood pressure or time spent [114], which has acted as a mediator in explaining certain behaviors.

Beside the above-mentioned concepts, such as affect, mood and emotions, table 1 and 3 include, fun, enjoyment and playfulness. According to gamification theory, these psychological constructs are partly interwoven in other concepts such as flow. According to many studies in gamification, the aspect of fun $[41,54,55,70,86]$ constitutes various contextual outcomes such as solving tasks, contribution, app use, quality worker performances and so forth. With regard to enjoyment and playfulness, these are often synonymously used with the concept of fun [17].

\subsubsection{Purpose, autonomy and other}

Purpose seems to be a concept of relevance for gamification as there is a myriad of studies discussing it in various ways. Some closely related semantic meanings are goals, purposefulness, purpose, contribution, relevance, accomplishment, growth, usefulness, responsibility and meaning. These signify that purpose is a driver for motivation and engagement. While mechanics can be tailored to provide a pre-conditioned purpose, such as stating a goal for the player, there are studies that confer purposefulness as a feeling or a mental state rather than purpose. In common games, there is usually a beginning and an 
end, with the end being the goal for the tasks involved in reaching it. Researchers including Burke [13] state that goals are highly important for motivating employees, indicating that goals are a prerequisite for motivation and not the other way around. Thus, purpose is related to motivation in the context of gamification, which Roengsamut et al. [63] agree belongs to the concept of intrinsic motivation.

While autonomy is also related to intrinsic motivation [63], it demonstrates the feeling of choice and freedom. Table 3 shows that common concepts that encompass autonomy are perceived as choice, empowerment, trust and self-efficacy and this also indicates a sense of control. According to psychology, this sense of control is important, and the perception of it has a positive impact on health and relationships [117]. In the context of gamification, this autonomy or self-governance can be influenced by letting individuals choose their own pace in online courses, or as Burgun [118] says that nonlinearity in games provides choices which simulate autonomy. The motivating aspect can be related to the fact that the concept of autonomy distances itself from the perspective of being cogent, work-related or boring. This gives additional input for motivation and provides meaning to people without overusing rewards [119]. Hence, Nicholson [119] indicates a relation between meaningfulness, purposefulness and autonomy.

Some additional contexts are attitude, comprehensible, low effort, addiction, relatedness, commitment, moral, perceived value, acceptance and novelty [8, 40, 63]. Each of these concepts can be argued as encompassing each other, such as attitude being a component of affect or vice versa, but future research will reveal the importance of the relative importance of these in the context of gamification.

\subsection{Outcomes}

As discussed in the theoretical framework (figure 1) and in the conceptual discussion, outcomes are here reviewed as the desired outcome in the chain of applying gamification in a system, service or offering. Outcomes in studies occasionally also refer to psychological mediators and include the psychological concepts [7]. Thus, it can be difficult to specify an outcome as solely being behaviorally laden. Outcomes become hence a goal for pursuit, something that is hoped to be achieved via rather a psychological mediator. In most cases, these outcomes are behavioral (see table 1), but are also frequently a mixture of cognitive and behavioral concepts that are proxy for a context-specific theoretical discourse.

The outcomes vary a lot more than mechanics and mediators, which can respectively be categorized in several common denominators. Gamified outcomes vary not only in the specific domain, such as measuring acceptance and usability [86], save behavior [87] and intentions to engage [92] in the domain of sustainability; but they also vary drastically among the different domains. To illustrate the disparities in gamification literature, concepts of loyalty are highlighted in the domain of business and marketing [48], whilst concepts such as proof reading are highlighted in crowdsourcing literature [58], and recall precision is central in learning [71].

Despite of the conceptual variances in the outcomes of gamification, there seems to be a pattern of literature on the examination of improvements or performances. Regardless of domain, all outcomes can be structured among the following concepts. Economic meaning that the outcome is closely related to concept that benefit economic or organizational performance, purchasing being one of them [14,44], but also concepts that are closely approximate to the economic performance, brand equity, brand love or brand attitude $[10,45,53]$ or some tourism research that includes experiences and brand awareness [98]. Cognitive and emotional performances are more specifically mental performances, in terms of knowledge, learning and attitudes [11, 72, 74], or anxiety reduction [99, 107]. It must be noted that these outcomes differ in relation to psychological mediators, as these are crucial for stimulating subsequent outcomes and that these intermediaries are closely linked to gamification mechanics and their effect on people. As behaviors seem at first be a relevant candidate, in terms of cognition and emotions being 
one, there is a separation in how these behaviors are measured. Behavioral intent follows the premise of people via self-reports stating to behave in some way, for instance their intent to engagement [92] or Actual behaviors measure behaviors after employing stimuli to a platform $[88,90]$. Needless to say, outcomes are highly domain and context specific.

\subsection{Moderators}

While there are cultural differences and the increased efficiency of gamifying servicescapes [120], there is no doubt that younger people are more likely to be affected by gamification as a part of their everyday lives [121]. Consequently, literature suggests that demographics such as age and culture moderate the relationship between mechanics and the psychological mediators. Elements outside the individual, such as time and space, have also been shown to alter the relationships to some degree. Space, in terms of what type of service is provided, has in Hamari [43] study been shown to highlight utilitarian and hedonic features and how well people correspond to each of the elements. In regard to both time and space, Koivisto and Hamari [122] first show that gender and age moderate the perceived social benefits, while gamification functions best in the beginning in terms of the novelty of the service, meaning that there is some degradation of efficiency over time. However, many studies highlight the further need to inquire into the moderating effects in gamification [25, 109].

\subsection{Context and domain}

Gamification as a subject is still in its infancy but is starting to mature [25]. According to O'Donnell et al. [24] preliminary scoping review 739 (n) articles and 1245 (n) conferences exist in gamification, within several different domains. This paper reviewed studies that were of particular interest for the discourse of gamification literature [28, 29]. These are health and wellness, crowdsourcing, sustainability, computer science, software development, marketing and tourism. As discussed previously, there is no doubt that the context and domain control for which mechanics are used depend on which psychological mediators are activated and which outcomes are relevant. To illustrate this, while an advertising campaign may include mechanics that include quizzes and actual mini-games (mechanics) to engage (psychological mediators) the consumer to download (outcome) an application [123], similarly other contexts and domains have their own unique patterns. For instance, a health and wellness context may employ goals, path and progress (mechanics) to generate empowerment (psychological mediators), which subsequently mediates physical activity (outcome) [31]. However, it is dangerous to separate mechanics that belong uniquely to one specific domain. In table 2 the mechanics, psychological mediators and outcomes are separated according to domains. Firstly, it is shown that there are mechanics that are shared (e.g. leaderboards, badges and other in table 1) and some that are unique (e.g. user-generated content, gifting and other). The research into clearly categorizing these according to specific domains is still in development. One important factor is still the domain in which gamification is employed and controlled as to which outcomes are desired. The relationship between the domain/context and outcomes is bidirectional where the aim or purpose, as well as the context, controls how they are measured. The element of measurement refers to how outcomes are designed and what tools are employed when gathering data. Domains and contexts partly reflect outcomes, but also which mechanics are employed. While the domain and context cannot directly influence psychological mediators without going through mechanics, it implies that the domain controls what mechanics are appropriate [10]. This indicates that mechanics are to some extent domain specific, but that many of them are shared. Consequently, domains require the mechanics to be congruent in order to reach certain desired outcomes, as in Carvalho et al. [69], prior implementing them.

. Thus domain-congruent mechanics constitute the first step in gamifying a service or context $[2,14,48,124]$. 
pag. 16

\subsection{Goals, Strategy Vision}

As Burke [13] states, the reason for employing gamification has been to motivate people to change behaviors. The actor that chooses to implement a mechanic (mechanic) and seeks to motivate or engage (psychological mediator) people to change behaviors (outcome) is generally referred to as the designer of gamifying a context. This can either be done within organizations [18], or by external communication. Goal, strategy and vision represent the perspective of the actors who choose to apply gamification in a process, situation or service. While this research has adopted the perspective of gamification as an instrument or a tool for enhancing, changing and influencing outcomes [27], it also becomes important to understand the latent reasons behind why actors, managers or stakeholders commit to employing certain strategies that employ gamified mechanics in their processes. Without going into the potential relevant theories of reward management [125], where hierarchical reward mechanism can explain organizational drive, gamification research is rather multidisciplinary, complex and hence has several dimensions. Regardless of whether the goals, strategy and visions differ between a company and a teacher who aims to gamify a course, they all strive towards or are motivated to reach certain outcomes. Accordingly, outcomes are motivating factors for determining certain strategies, such as implementing gamification. These goals, visions or strategies subsequently determine which mechanics are implemented with the requirements of congruence to the domain and context.

\section{Conceptual Model: $M-P M-O$}

The conceptual discussion has highlighted potentially causative and correlational relationships between several concepts when gamifying a situation, context, service or/and process, thus have resulted in a conceptual model (figure 2). As there are manifold mechanics (table 1), it becomes difficult to show actual interferences. To illustrate, gifting can be seen as a part of socialization, but also as a mechanism for rewarding. Accordingly, it becomes difficult to contrast and strategically implement mechanics when they are multifaceted [24]. To facilitate understanding, some denominators (table 2) were developed which show that mechanics can be categorized in an interdisciplinary context. The review shows that domain-specific contexts have similar outcomes, indicating that 'desired outcomes' actually control which mechanics fit within the given context. Hence, the designer ought to first understand the context and situation before choosing appropriate mechanics with regards to its/her/his goals, vision and strategy. Implementing gamification is more complex than some practitioners and researchers dare to admit [13]. The conceptual discussion has revealed that the interaction effects between mechanics and their subsequent effects are complex. It becomes difficult to directly pinpoint how the mechanics work together to impact on emotions and behaviors. In literature, the mechanics are rather treated as stimuli which provoke responses [10]. While doing so, these stimuli could be examined in isolation as well as in combination. This perspective offers a multitude of new studies, primarily on the interaction effects between different mechanics and on either the psychological mediators or the contextual outcomes. Helmefalk and Marcusson (ibid.) do to some extent discuss this matter, in that some mechanics are more or less used, but that some are more evidently categorized within a certain context [2]. Consequently, mechanics have a two-way relationship to the context and the domain where mechanics need to be relevant and congruent to the specific context, domain or situation for it to be successful in influencing psychological mediators. The model emphasizes the importance of this, especially when being used in different context. Much of the literature takes this for granted as being niched towards a particular subject. Figure 2, emphasizes the importance of paying attention to the specific domain, context and situation.

A considerable volume of literature suggests that mechanics have an impact on various psychological outcomes [7, 30], defined as psychological mediators in this 
conceptual paper. While there is a range of different psychological effects being polysemantic and synonymous with each other, there are also some common denominators, such as affect, autonomy/ the sense of control, social, engagement/cognitive stimulation, incentive reinforcement/ motivation, other cognitive factors, knowledge, purpose, meaning and fulfillment (figure 2). Although some studies investigate these mediators as the final outcome, there is no doubt that many do function as arbitrators for something that is desired in a given context. The one that implements mechanics rarely wants to achieve, for instance, motivation, without it impacting on some outcomes, such as motivation to perform better at a given task. Thus, there needs to be a separation between these two, at least when examining how people are affected by gamification. The conceptual model in figure 2 , emphasizes this distinction between a psychological and behavioral outcome, moreover, does not treat them equally. This distinction also offers opportunity to understand the sequential and mediating effects of mechanics on psychological mediators and its subsequent effect on outcomes.

The causal effects of mechanics on psychological mediators are not completely linear, but are moderated, not only by the interaction effects of mechanics [126], but also by various external moderators. This review has discussed that culture can moderate these relationships [120], but also the ages of people involved, and this is indirectly explained by their experience of gaming and familiarity with game dynamics [122]. Moreover, Hamari [43] has shown that places, in terms of platforms, and the degradation of novelty have an impact on various outcomes. Thus, there is an aspect of time and space within gamification literature that moderates the efficiency of gamification.

With regard to the ample outcomes there are many more to consider, but mainly those that are context-dependent, for example while the business domain tends to consider purchasing behaviors [8, 44], learning instead examines learning outcomes [73, 74]. Likewise, the context and the domain control what methods are appropriate and what outcomes are desired. Each domain has their own preferred methods for examining and measuring theoretically different concepts. Consequently, this is motivated by the organization's goals, vision or strategies. It becomes hence a feedback loop where the organization or actor implements the mechanics in relation to what is desired and which ones seem reasonable.

While other conceptual models $[10,46]$ recognize the importance of mechanics and outcomes, this conceptual model recognizes that there are domain-congruent mechanics which fit more or less in a given context. This model sheds light, and presents a novel view on gamification in different contexts and domains, which can be further elaborated and researched on regardless the domain.

To further illustrate the model an example will be provided. A business that wants to modify its current retail space, has to first determine the desired outcome of considering gamifying a service or process. The outcomes are in this case of an economic and cognitive nature, such as increasing products sold or attitude. These are usually in line with and motivated by the current goals, strategies or visions of the firm. The second step is to determine the congruency between mechanics and context. For example, a manager needs to consider what mechanics, in table 2, would fit inside the specific store and service, simultaneously while trying to grasp how the consumer will be psychologically impacted in table 3. A possible solution could be to implement geo-location map hunting for sale codes, with progress paths and point trackers, mediating through arousal, subsequently on purchasing. As there still exists a colossal research gap in understanding which mechanic impacts and mediates on what outcome, there is still room to explore, map out, and measure these linkages. Thus, an important consideration is to empirically evidence the multitude of nodes and different paths that exist between mechanics, psychology mediators and outcomes. While investigating these, there also exist potential moderators that can be further tweaked to statistically investigate how these variables impact on the relationship between consumers and their psychology, such as type of store, type of consumer, age, lifestyle, culture, time of the day, online vs. physical store, and many other moderators. 
In summary, the model considers several aspects: the mechanics, psychological mediators, outcomes, the goals/strategy/vision, and the context/domain in which they are studied and employed.

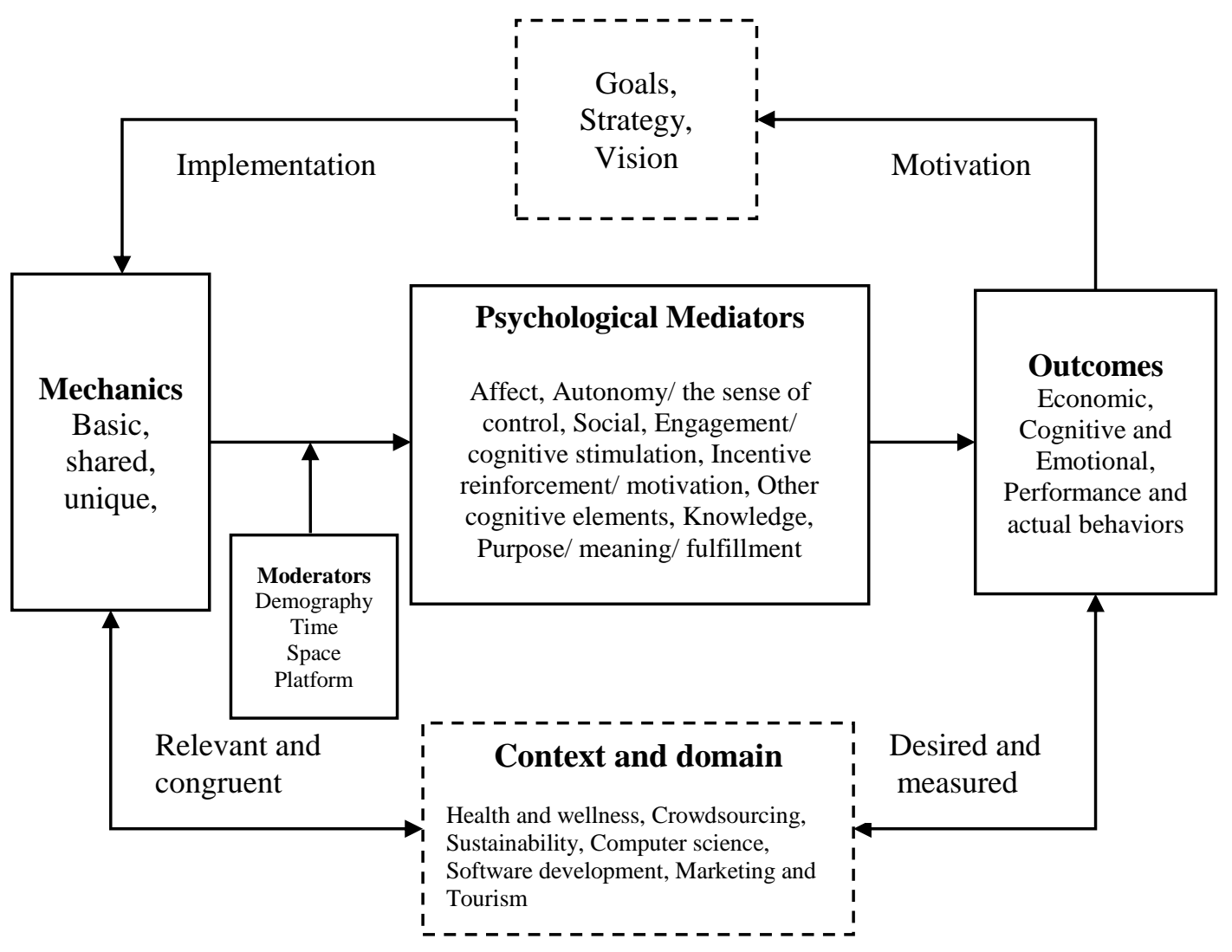

Figure 2. The framework for gamification: $M-P M-O$

\section{Conclusion and discussion}

This study develops the notion of gamification from a concept that only seeks to motivate people to alter their behavior towards one with innumerable opportunities in many different contexts.

To answer the research question: how does gamification literature portray the effects of mechanics, psychological mediators and outcomes multi-disciplinary, this research presents an alternative and uniform perspective on the broad gamification research to better understand how gamification functions and can be employed to impact various outcomes; regardless of whether it is in the domain of health, crowdsourcing, sustainability, computer science, software development, marketing or tourism. This research contributes to this rather eclectic domain [24], presenting a more categorized view in showing domainspecific mechanics and how these can be employed for empirical testing.

While the present research is rather interdisciplinary, it subsequently shows that gamification has rapidly grown into being a potent theory. Morschheuser et al. [127] state that "It is not enough to execute the gamification design in a technically stellar manner but also the manifold and multidimensional aspects of context, user psychology and engagement have to guide the design". This assertion is in line with Burke [13] which indicates that while there is a causative relationship between mechanics, psychological mediators and outcomes, it is important to understand how these function in order to implement successful gamification. 
As mentioned, the conceptual model (figure 2) contributes an understanding of how a person or organization can employ mechanics to reach certain outcomes. To illustrate the model, for example in educational learning settings, there are mechanics that fit more or less together in these contexts (see table 1 for inspiration). While there are always mechanics that are to some extent used in every scenario, such as badges, points and leaderboards, there are some that are used more frequently in some domains and situations than in other. Depending on what mechanics are employed, these will impact differently on psychological mediators. Subsequently, these will have different effects on outcomes, which in this case may be concepts, such as learning or participation. Thus, outcomes need to be carefully considered before strategically employing mechanics, as the causative chain from mechanics, to mediators and lastly to outcomes are complex and relatively unexplored.

There has been an increase in systematic reviews on gamification without the empirical data to support the bulk of literature. However, more empirical literature is needed, both of quality, and of variety. As the empirical contribution has been rather scarce $[1,111]$, this conceptual model can be modified, employed and adjusted to investigate various effects of gamification on outcomes in all the domains mentioned in this paper. More research is required within each of the effects in table 1, and this needs to be further developed and empirically tested.

It must also be noted that there are other domains and newly emerging ones that also employ gamification. To further develop the conceptual discussion, these should also be analyzed and further investigated.

Looking at all the possible mechanics, mediators, outcomes, contexts, there are exponentially endless possibilities for further research within gamification. Nacke and Deterding [25] state that gamification has reached a maturity in a sense, this present research suggest that a new wave of gamification research should be developed where field and laboratory experiments [126] will further evolve gamification.

This research has suggested and presented linkages between concepts, but it becomes harder to find evidence for the causal relationship between these. The more evident ones are the ones between mechanics, psychological mediators and outcomes. Within these, it becomes more difficult to pinpoint any evidence portraying a conceptual or a predictive structural model.

Thus, it becomes interesting to understand and further examine how emotions correlate with or predict other mediators in different gamified contexts. For instance, the concept of motivation, as a prerequisite for other psychological mediators, is maybe not so strange as the word itself indicates a followed action. A motivation could also constitute a purpose or an incentive, which further draws a link between the actual self-experienced purpose and other arbitrators.

As this research has shown that stimuli could be examined in isolation as well as in combination, a multitude of new studies, primarily on the interaction effects between different mechanics and on either the psychological mediators or the contextual outcomes are recommended. Further research on this matter would map out the scarce evidence of how much each mechanic, and when in interplay with each other, influences actual outcomes, and how much the mediators influence their relationship.

In literature, there seems to be a difficulty when conceptualizing the actor(s) that gamifies the process or service. In regards to gamification as an interdisciplinary theory, there ought not to be a difference whether it is a person or an organization that is in control for implementing mechanics. Thus, there is a need of conceptually unifying the notion of what or who is gamifying a service or process. 
[1] J. Kasurinen and A. Knutas, Publication trends in gamification: A systematic mapping $\begin{array}{lllll}\text { study. Computer } \quad \text { Science } \quad \text { Review, } & 27 \text { : } & \text { p. }\end{array}$ https://doi.org/10.1016/j.cosrev.2017.10.003

[2] K. Seaborn, and D.I. Fels, Gamification in theory and action: A survey. International Journal of Human-Computer Studies, 74: p. 14-31,2015. https://doi.org/10.1016/j.ijhcs.2014.09.006

[3] J.M Kumar and M. Herger, Gamification at Work: Designing Engaging Business Software Interaction Design Foundation, 2013: https://doi.org/10.1145/2468356.2468793

[4] B Burke, Gamify: How Gamification motivates people to do extraordinary things. Bibliomotion. Inc., Apr, 2014.

[5] J. Hamari, J. Koivisto, and H. Sarsa. Does gamification work?--a literature review of empirical studies on gamification. in System Sciences (HICSS), 2014 47th Hawaii International Conference on. 2014. IEEE.

[6] K. Robson, K. Plangger, J.H. Kietzmann, I. McCarthy, and L. Pitt, Is it all a game? Understanding the principles of gamification. Business Horizons, 2015. 58(4): p. 411-420. https://doi.org/10.1016/j.bushor.2015.03.006

[7] C. Dichev and D. Dicheva, Gamifying education: what is known, what is believed and what remains uncertain: a critical review. International journal of educational technology in higher education, 14(1): p. 9, 2017.

[8] Cochoy and Hagberg, The Business of Gamification: A Critical Analysis, M. Dymek and P. Zackariasson, Editors, Routledge. p. 81-99, 2016. https://doi.org/10.4324/9781315740867

[9] R.N. Landers, E.M. Auer, A.B. Collmus, and M.B. Armstrong, Gamification science, its history and future: Definitions and a research agenda. Simulation \& Gaming, p. 1046878118774385,2018. https://doi.org/10.1177/1046878118774385

[10] M. Helmefalk and L. Marcusson, Gamification in a servicescape context: A conceptual framework. International Journal of Internet Marketing and Advertising, In Press.

[11] R.K. Pettit, L. McCoy, M. Kinney, and F.N. Schwartz, Student perceptions of gamified audience response system interactions in large group lectures and via lecture capture technology. BMC medical education, 15(1): p. 92, 2015. https://doi.org/10.1186/s12909-0150373-7

[12] Su, C.H. and C.H. Cheng, A mobile gamification learning system for improving the learning motivation and achievements. Journal of Computer Assisted Learning, 31(3): p.268-286, 2015. https://doi.org/10.1111/jcal.12088

[13] B. Burke, Gamify: How gamification motivates people to do extraordinary things. 2016: Routledge https://doi.org/10.4324/9781315230344

[14] T. Harwood and T. Garry, An investigation into gamification as a customer engagement experience environment. Journal of Services Marketing,. 29(6-7): p. 533-546, 2015. https://doi.org/10.1108/JSM-01-2015-0045

[15] K. Huotari and J. Hamari, A definition for gamification: anchoring gamification in the service marketing literature. Electronic Markets, 27(1): p. 21-31, 2017. https://doi.org/10.1007/s12525-015-0212-z

[16] D. Johnson, E. Horton, R. Mulcahy and M. Foth, Gamification and serious games within the domain of domestic energy consumption: A systematic review. Renewable and Sustainable Energy Reviews, 73: p. 249-264, 2017. https://doi.org/10.1016/j.rser.2017.01.134

[17] B. Morschheuser, J. Hamari, J. Koivisto, and A. Maedche, Gamified crowdsourcing: Conceptualization, literature review, and future agenda. International Journal of HumanComputer Studies, 106: p. 26-43, 2017 https://doi.org/10.1016/j.ijhcs.2017.04.005

[18] M. Vesa, J. Hamari, J.T. Harviainen, and H. Warmelink, Computer games and organization

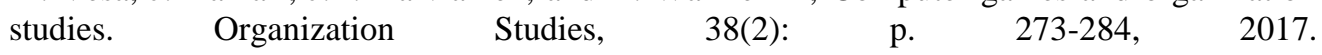
https://doi.org/10.1177/0170840616663242

[19] J. Hamari, Do badges increase user activity? A field experiment on the effects of gamification. Computers in Human Behavior, 71: p. 469-478.,2017. https://doi.org/10.1016/j.chb.2015.03.036

[20] S. Dale, Gamification: Making work fun, or making fun of work? Business Information Review, 31(2): p. 82-90, 2014. https://doi.org/10.1177/0266382114538350

[21] A. Allam, Z. Kostova, K. Nakamoto, and J.P. Schulz, The Effect of Social Support Features and Gamification on a Web-Based Intervention for Rheumatoid Arthritis Patients: Randomized Controlled Trial. J Med Internet Res, 17(1): p. e14, 2015. https://doi.org/10.2196/jmir.3510. 
[22] M.D. Hanus and J. Fox, Assessing the effects of gamification in the classroom: A longitudinal study on intrinsic motivation, social comparison, satisfaction, effort, and academic performance. Computers \& Education, 80: p. 152-161, 2015. https://doi.org/10.1016/j.compedu.2014.08.019

[23] M. Sailer, J.U. Hense, S.K. Mayr, and H. Mandl, How gamification motivates: An experimental study of the effects of specific game design elements on psychological need satisfaction. Computers in Human Behavior, 69: p. 371-380, 2017. https://doi.org/10.1016/j.chb.2016.12.033

[24] N. O'Donnell, D.L. Kappen, Z. Fitz-Walter, S. Deterding, L.E. Nacke, and D. Johnson. How Multidisciplinary is Gamification Research?: Results from a Scoping Review. in Extended Abstracts Publication of the Annual Symposium on Computer-Human Interaction in Play. ACM, 2017.

[25] L.E. Nacke and S. Deterding, The maturing of gamification research. Computers in Human Behavior, 71: p. 450-454, 2017. https://doi.org/10.1016/j.chb.2016.11.062

[26] S. Deterding, D. Dixon, R. Khaled, and L. Nacke. From game design elements to gamefulness: defining gamification. in Proceedings of the 15th international academic MindTrek conference: Envisioning future media environments, ACM, 2011.

[27] K. Werbach and D. Hunter, For the win: How game thinking can revolutionize your business, Wharton Digital Press, 2012

[28] A.S. Miller, J.A. Cafazzo and E. Seto, A game plan: Gamification design principles in mHealth applications for chronic disease management. Health informatics journal, 2016. 22(2): p. 184193. https://doi.org/10.1177/1460458214537511

[29] T. Wolf, W.H. Weiger and M. Hammerschmidt. Gamified Digital Services: How Gameful Experiences Drive Continued Service Usage. in Proceedings of the 51 st Hawaii International Conference on System Sciences, 2018. https://doi.org/10.24251/HICSS.2018.147

[30] R. Hervas, D. Ruiz-Carrasco, T. Mondejar and J. Bravo. Gamification mechanics for behavioral change: a systematic review and proposed taxonomy. in Proceedings of the 11th EAI International Conference on Pervasive Computing Technologies for Healthcare, ACM. 2017. https://doi.org/10.1145/3154862.3154939

[31] D. Johnson, S. Deterding, K.-A. Kuhn, A. Staneva, S. Stoyanov and L. Hides, Gamification for health and wellbeing: A systematic review of the literature. Internet Interventions, 6: p. 89-106, 2016. https://doi.org/10.1016/j.invent.2016.10.002

[32] T. Alahäivälä and H. Oinas-Kukkonen, Understanding persuasion contexts in health gamification: A systematic analysis of gamified health behavior change support systems literature. International Journal of Medical Informatics, 96: p. 62-70, 2016. https://doi.org/10.1016/j.ijmedinf.2016.02.006

[33] C.F. Hofacker, K. de Ruyter, N.H. Lurie, P. Manchanda and J. Donaldson, Gamification and Mobile Marketing Effectiveness. Journal of Interactive Marketing, 34: p. 25-36, 2016.

[34] M.D. Gall, W.R. Borg and J.P. Gall, Educational research: An introduction. 1996: Longman Publishing. https://doi.org/10.1016/j.intmar.2016.03.001

[35] C. Hart, Doing a literature review: Releasing the social science research imagination. 1998, London: UK: Sage Publications.

[36] J.J. Randolph, A guide to writing the dissertation literature review. Practical Assessment, Research \& Evaluation, 14(13): p. 1-13, 2009.

[37] K. Dwan, D. Altman, J.A. Arnaiz, J. Bloom, A.W. Chan, E. Cronin, . . . P.R. Williamson, Systematic review of the empirical evidence of study publication bias and outcome reporting bias. PLoS One, 3(8): p. 1-31, 2008. https://doi.org/10.1371/journal.pone.0003081

[38] A. Matallaoui, J. Koivisto, J. Hamari, and R. Zarnekow. How Effective Is "Exergamification”? A Systematic Review on the Effectiveness of Gamification Features in Exergames. in Proceedings of the 50th Hawaii International Conference on System Sciences. 2017. https://doi.org/10.24251/HICSS.2017.402

[39] L. Sardi, A. Idri and J.L. Fernández-Alemán, A systematic review of gamification in e-health. Journal of biomedical informatics, 71: p. $31-48, \quad 2017$. https://doi.org/10.1016/j.jbi.2017.05.011

[40] J.V. Bittner and J. Schipper, Motivational effects and age differences of gamification in product advertising. Journal of Consumer Marketing, 31(5): p. 391-400, 2014. https://doi.org/10.1108/JCM-04-2014-0945

[41] R. Conaway and M.C. Garay, Gamification and service marketing. Springerplus, 3(1): p. 653, 2014. https://doi.org/10.1186/2193-1801-3-653 
pag. 22

[42] M. Dymek, The Business of Gamification: A Critical Analysis, M. Dymek and P. Zackariasson, Editors, Routledge. p. 99-122, 2016. https://doi.org/10.4324/9781315740867

[43] J. Hamari, Transforming homo economicus into homo ludens: A field experiment on gamification in a utilitarian peer-to-peer trading service. Electronic Commerce Research and Applications, 12(4): p. 236-245, 2013. https://doi.org/10.1016/j.elerap.2013.01.004

[44] M. Holzwarth, C. Janiszewski, and M.M. Neumann, The influence of avatars on online consumer shopping behavior. Journal of Marketing, 70(4): p. 19-36, 2006. https://doi.org/10.1509/jmkg.70.4.019

[45] C.-L Hsu and M.-C. Chen, How gamification marketing activities motivate desirable consumer behaviors: Focusing on the role of brand love. Computers in Human Behavior, 88: p. 121-133, 2018. https://doi.org/10.1016/j.chb.2018.06.037

[46] K. Huotari and J. Hamari. Defining gamification: a service marketing perspective. in Proceeding of the 16th International Academic MindTrek Conference, ACM. 2012. https://doi.org/10.1145/2393132.2393137

[47] V. Insley and D. Nunan, Gamification and the online retail experience. International Journal of Retail \& Distribution Management, 42(5): p. 340-351, 2014. https://doi.org/10.1108/IJRDM01-2013-0030

[48] G. Lucassen and S. Jansen, Gamification in Consumer Marketing-Future or Fallacy ProcediaSocial and Behavioral Sciences, 148: p. 2014. https://doi.org/10.1016/j.sbspro.2014.07.034

[49] J. Müller-Stewens, T. Schlager, G. Häubl and A. Herrmann, Gamified information presentation and consumer adoption of product innovations. Journal of Marketing, 81(2): p. 8-24. 2017. https://doi.org/10.1509/jm.15.0396

[50] K. Robson, K. Plangger, J. Kietzmann, I. McCarthy and L. Pitt, Understanding gamification of consumer experiences. NA-Advances in Consumer Research Volume 42, 2014.

[51] L.F Rodrigues, A. Oliveira, and C.J. Costa, Does ease-of-use contributes to the perception of enjoyment? A case of gamification in e-banking. Computers in Human Behavior, 61: p. 114126, 2016. https://doi.org/10.1016/j.chb.2016.03.015

[52] M. Witt, C. Scheiner and S. Robra-Bissantz, Gamification of online idea competitions: Insights from an explorative case. Informatik schafft Communities, 192, 2011.

[53] Y.Yang, Y. Asaad and Y. Dwivedi, Examining the impact of gamification on intention of engagement and brand attitude in the marketing context. Computers in Human Behavior, 73: p. 459-469, 2017. https://doi.org/10.1016/j.chb.2017.03.066

[54] M. Altmeyer, P. Lessel and A. Krüger. Expense control: a gamified, semi-automated, crowdbased approach for receipt capturing. in Proceedings of the 21 st International Conference on Intelligent User Interfaces, ACM, 2016. https://doi.org/10.1145/2856767.2856790

[55] A.Bowser, D. Hansen, Y. He, C. Boston, M. Reid, L. Gunnell, and J. Preece. Using gamification to inspire new citizen science volunteers. in Proceedings of the first international conference on gameful design, research, and applications, ACM. 2013. https://doi.org/10.1145/2583008.2583011

[56] C. Eickhoff, C.G. Harris, A.P. de Vries, and P. Srinivasan. Quality through flow and immersion: gamifying crowdsourced relevance assessments. in Proceedings of the 35th international ACM SIGIR conference on Research and development in information retrieval, ACM, 2012. https://doi.org/10.1145/2348283.2348400

[57] Y. Feng, H.J. Ye, Y. Yu, C. Yang and T. Cui, Gamification artifacts and crowdsourcing participation: Examining the mediating role of intrinsic motivations. Computers in Human Behavior, 81: p. 124-136m 2018. https://doi.org/10.1016/j.chb.2017.12.018

[58] T. Itoko, S. Arita, M. Kobayashi and H. Takagi. Involving senior workers in crowdsourced proofreading. in International Conference on Universal Access in Human-Computer Interaction, Springer 2014. https://doi.org/10.1007/978-3-319-07446-7_11

[59] R. Kawajiri, M. Shimosaka and H. Kashima. Steered crowdsensing: Incentive design towards quality-oriented place-centric crowdsensing. in Proceedings of the 2014 ACM International Joint Conference on Pervasive and Ubiquitous Computing, ACM. 2014. https://doi.org/10.1145/2632048.2636064

[60] M. Kobayashi, S. Arita, T. Itoko, S. Saito and H. Takagi. Motivating multi-generational crowd workers in social-purpose work. in Proceedings of the 18th ACM Conference on Computer Supported Cooperative Work \& Social Computing, ACM , 2015. https://doi.org/10.1145/2675133.2675255 
[61] C. Preist, E. Massung and D. Coyle. Competing or aiming to be average?: normification as a means of engaging digital volunteers. in Proceedings of the 17th ACM conference on Computer supported cooperative work \& social computing, ACM., 2014.

[62] N.R. Prestopnik and J. Tang, Points, stories, worlds, and diegesis: Comparing player experiences in two citizen science games. Computers in Human Behavior, 52: p. 492-506, 2015. https://doi.org/10.1016/j.chb.2015.05.051

[63] B. Roengsamut, K. Kuwabara and H.-H. Huang. Toward gamification of knowledge base construction. in Innovations in Intelligent SysTems and Applications (INISTA), 2015 International Symposium on, IEEE, 2015..

[64] R. Snijders, F. Dalpiaz, S. Brinkkemper, M. Hosseini, R. Ali and A. Ozum. REfine: A gamified platform for participatory requirements engineering. in Crowd-Based Requirements Engineering (CrowdRE), 2015 IEEE 1st International Workshop on, IEEE, 2015.

[65] R. Tinati, M. Luczak-Roesch, E. Simperl, and W. Hall. Because science is awesome: studying participation in a citizen science game. in Proceedings of the 8th ACM Conference on Web Science, ACM, 2016. https://doi.org/10.1145/2908131.2908151

[66] Z. Zeng, J. Tang and T. Wang, Motivation mechanism of gamification in crowdsourcing projects. International Journal of Crowd Science, 1(1): p. 71-82, 2017. https://doi.org/10.1108/IJCS-12-2016-0001

[67] S. Arnab, T. Lim, M.B. Carvalho, F. Bellotti, S. De Freitas, S. Louchart, . . A.J.B.J.o.E.T. De Gloria, Mapping learning and game mechanics for serious games analysis. 46(2): p. 391-411, 2015.

[68] M.T. Bonde, G. Makransky, J. Wandall, M.V. Larsen, M. Morsing, H. Jarmer and M.O. Sommer, Improving biotech education through gamified laboratory simulations. Nature biotechnology, 32(7): p. 694, 2014. https://doi.org/10.1038/nbt.2955

[69] M.B. Carvalho, F. Bellotti, R. Berta, A. De Gloria, C.I. Sedano, J.B. Hauge, . . education, An activity theory-based model for serious games analysis and conceptual design, 87: p. 166-181, 2015.

[70] L. Hakulinen, T. Auvinen and A. Korhonen, The effect of achievement badges on students' behavior: An empirical study in a university-level computer science course. International Journal of Emerging Technologies in Learning (iJET), 10(1): p. 18-29, 2015. https://doi.org/10.3991/ijet.v10i1.4221

[71] T. Hasegawa, M. Koshino and H. Ban, An English vocabulary learning support system for the learner's sustainable motivation. SpringerPlus, 4(1): p. 2015. https://doi.org/10.1186/s40064-015-0792-2

[72] C. Holman, S. Aguilar and B. Fishman. GradeCraft: What can we learn from a game-inspired learning management system? in Proceedings of the third international conference on learning analytics and knowledge, ACM , 2013. https://doi.org/10.1145/2460296.2460350

[73] M. Krause, M. Mogalle, H. Pohl and J.J. Williams. A playful game changer: Fostering student retention in online education with social gamification. in Proceedings of the Second (2015) ACM Conference on Learning@ Scale, ACM , 2015. https://doi.org/10.1145/2724660.2724665

[74] T. Lehtonen, T. Aho, E. Isohanni and T. Mikkonen. On the role of gamification and localization in an open online learning environment: javala experiences. in Proceedings of the 15th Koli Calling Conference on Computing Education Research, ACM, 2015. https://doi.org/10.1145/2828959.2828973

[75] C.R. Nevin, A.O. Westfall, J.M. Rodriguez, D.M. Dempsey, A. Cherrington, B. Roy, J.H. Willig, Gamification as a tool for enhancing graduate medical education. Postgraduate medical journal, p. postgradmedj-2013-132486, 2014:

[76] L.Z. Pedro, A.M. Lopes, B.G. Prates, J. Vassileva and S. Isotani. Does gamification work for boys and girls?: An exploratory study with a virtual learning environment. in Proceedings of the 30th annual ACM symposium on applied computing, ACM, 2015. https://doi.org/10.1145/2695664.2695752

[77] D. Ašeriškis and R. Damaševičius. Gamification of a Project management system. in Proc. of Int. Conference on Advances in Computer-Human Interactions ACHI2014, Citeseer, 2014.

[78] I. Carmosino, F. Bellotti, R. Berta, A. De Gloria and N.J.E.C. Secco, A game engine plug-in for efficient development of investigation mechanics in serious games. 2017. 19: p. 1-11.

[79] A.A de Melo, M. Hinz, G. Scheibel, C.D.M. Berkenbrock, I. Gasparini and F. Baldo. Version Control System Gamification: A proposal to encourage the engagement of developers to 
collaborate in software projects. in International Conference on Social Computing and Social Media., Springer, 2014. https://doi.org/10.1007/978-3-319-07632-4_52

[80] S. Dencheva, C.R. Prause and W. Prinz. Dynamic self-moderation in a corporate wiki to improve participation and contribution quality. in ECSCW 2011: Proceedings of the 12th European Conference on Computer Supported Cooperative Work, 24-28 September, Aarhus Denmark, Springer, 2011. https://doi.org/10.1007/978-0-85729-913-0_1

[81] J. Fernandes, D. Duarte, C. Ribeiro, C. Farinha, J.M. Pereira and M.M. da Silva, iThink: A game-based approach towards improving collaboration and participation in requirement elicitation. Procedia Computer Science, 15: p. 66-77, 2012. https://doi.org/10.1016/j.procs.2012.10.059

[82] M. Foucault, X. Blanc, M.-A. Storey, J.-R. Falleri and C. Teyton, Gamification: a Game Changer for Managing Technical Debt? A Design Study. arXiv preprint arXiv:1802.02693, 2018.

[83] W. Snipes, A.R. Nair and E. Murphy-Hill. Experiences gamifying developer adoption of practices and tools. in Companion Proceedings of the 36th International Conference on Software Engineering, ACM, 2014.

[84] R. Sukale and M.S. Pfaff. QuoDocs: Improving developer engagement in software documentation through gamification. in CHI'14 Extended Abstracts on Human Factors in Computing Systems, ACM, 2014. https://doi.org/10.1145/2559206.2581263

[85] J. Thom, D. Millen and J. DiMicco. Removing gamification from an enterprise SNS. in Proceedings of the acm 2012 conference on computer supported cooperative work, ACM, 2012. https://doi.org/10.1145/2145204.2145362

[86] L. Gamberini, N. Corradi, L. Zamboni, M. Perotti, C. Cadenazzi, S. Mandressi, . . . C. Björkskog. Saving is fun: designing a persuasive game for power conservation. in Proceedings of the 8th international conference on advances in computer entertainment technology, ACM , 2011.

[87] D. Geelen, D. Keyson, S. Boess and H. Brezet, Exploring the use of a game to stimulate energy saving in households. Journal of Design Research 14, 10(1-2): p. 102-120, 2012.

[88] A. Gustafsson, C. Katzeff,and M. Bang, Evaluation of a pervasive game for domestic energy engagement among teenagers. Computers in Entertainment (CIE), 7(4): p. 54, 2009. https://doi.org/10.1145/1658866.1658873

[89] E. Knol and P.W. De Vries, EnerCities-A serious game to stimulate sustainability and energy conservation: Preliminary results. 2011.

[90] L. Morganti, F. Pallavicini, E. Cadel, A. Candelieri, F. Archetti and F. Mantovani, Gaming for Earth: Serious games and gamification to engage consumers in pro-environmental behaviours for energy efficiency. Energy Research \& Social Science, 29: p. 95-102, 2017. https://doi.org/10.1016/j.erss.2017.05.001

[91] R. Salvador, T. Romão and P. Centieiro, A gesture interface game for energy consumption awareness, in Advances in Computer Entertainment., Springer. p. 352-367, 2012, https://doi.org/10.1007/978-3-642-34292-9_25

[92] M. Senbel, V.D. Ngo and E. Blair, Social mobilization of climate change: University students conserving energy through multiple pathways for peer engagement. Journal of Environmental Psychology, 38: p. 84-93,2014. https://doi.org/10.1016/j.jenvp.2014.01.001

[93] R. Stone, R. Guest, S. Pahl and C. Boomsma. Exploiting gaming technologies to visualise dynamic thermal qualities of a domestic dwelling: Pilot study of an interactive virtual apartment. in Behave Energy Conference. 2014.

[94] R. Egger and P. Bulencea, Gamification in tourism: Designing memorable experiences. BoDBooks on Demand, 2015

[95] N.S. Sever, G.N. Sever and S. Kuhzady, The Evaluation of Potentials of Gamification in Tourism Marketing Communication. International Journal of Academic Research in Business and Social Sciences, 5(10):p. 188-202, 2015. https://doi.org/10.6007/IJARBSS/v5-i10/1867

[96] M. Sigala, The application and impact of gamification funware on trip planning and experiences: The case of TripAdvisor's funware. Electronic Markets, 25(3): p. 189-209, 2015. https://doi.org/10.1007/s12525-014-0179-1

[97] F. Xu, F. Tian, D. Buhalis, J. Weber, and H. Zhang, Tourists as mobile gamers: Gamification for tourism marketing. Journal of Travel \& Tourism Marketing, 33(8): p. 1124-1142, 2016. https://doi.org/10.1080/10548408.2015.1093999

[98] F. Xu, D. Buhalis and J. Weber, Serious games and the gamification of tourism. Tourism Management, 60: p. 244-256, 2017. https://doi.org/10.1016/j.tourman.2016.11.020 
[99] A. Ahtinen, E. Mattila, P. Välkkynen, K. Kaipainen, T. Vanhala, M. Ermes, .. R. Lappalainen, Mobile Mental Wellness Training for Stress Management: Feasibility and Design Implications Based on a One-Month Field Study. JMIR Mhealth Uhealth, 1(2): p. e11, 2013. https://doi.org/10.2196/mhealth.2596

[100] Y. Chen and P. Pu, HealthyTogether: exploring social incentives for mobile fitness applications, in Proceedings of the Second International Symposium of Chinese CHI. ACM: Toronto, Ontario, Canada. p. 25-34, 2014. https://doi.org/10.1145/2592235.2592240

[101] T.M.Fleming, L. Bavin, K. Stasiak, E. Hermansson-Webb, S.N. Merry, C. Cheek, . . . S. Hetrick, Serious games and gamification for mental health: current status and promising directions. Frontiers in psychiatry, 7: p. 215, 2017. https://doi.org/10.3389/fpsyt.2016.00215

[102] J. Hamari and J. Koivisto, "Working out for likes": An empirical study on social influence in exercise gamification. Computers in Human Behavior, 50: p. 333-347, 2015. https://doi.org/10.1016/j.chb.2015.04.018

[103] A. Kadomura, K. Tsukada and I. Siio, EducaTableware: Sound Emitting Tableware for Encouraging Dietary Education. Journal of Information Processing, 22(2): p. 325-333, 2014. https://doi.org/10.2197/ipsjjip.22.325

[104] I. Kuramoto, T. Ishibashi, K. Yamamoto, and Y. Tsujino. Stand Up, Heroes! : Gamification for Standing People on Crowded Public Transportation. in Design, User Experience, and Usability. Health, Learning, Playing, Cultural, and Cross-Cultural User Experience, Berlin, Heidelberg: Springer Berlin Heidelberg, 2013. https://doi.org/10.1007/978-3-642-39241-2_59

[105] S. Riva, A.-L. Camerini, A. Allam and J.P. Schulz, Interactive Sections of an Internet-Based Intervention Increase Empowerment of Chronic Back Pain Patients: Randomized Controlled Trial. J Med Internet Res, 16(8): p. e180, 2014. https://doi.org/10.2196/jmir.3474

[106] K.Thorsteinsen, J. Vittersö and G.B. Svendsen, Increasing Physical Activity Efficiently: An Experimental Pilot Study of a Website and Mobile Phone Intervention. International Journal of Telemedicine and Applications, p. 9, 2014. https://doi.org/10.1155/2014/746232

[107] A.D Tracy and J.O.T. Laura, Mental Health on the Go: Effects of a Gamified Attention-Bias Modification Mobile Application in Trait-Anxious Adults. Clinical Psychological Science, 2(5): p. 576-590, 2014. https://doi.org/10.1177/2167702614522228

[108] D.M. Whittinghill, Gamification of physical therapy for the treatment of pediatric cerebral palsy: a pilot study examining player preferences. age, 24: p. 1, 2014.

[109] R.N. Landers, K.N. Bauer and R.C. Callan, Gamification of task performance with leaderboards: A goal setting experiment. Computers in Human Behavior, 71: p. 508-515, 2017. https://doi.org/10.1016/j.chb.2015.08.008

[110] D. Dicheva, C. Dichev, G. Agre and G. Angelova, Gamification in education: A systematic mapping study. Journal of Educational Technology \& Society, 18(3), 2015.

[111] O. Pedreira, F. García, N. Brisaboa and M. Piattini, Gamification in software engineering- A systematic mapping. Information and Software Technology, 57: p. 157-168, 2015. https://doi.org/10.1016/j.infsof.2014.08.007

[112] A. Perttula, K. Kiili, A. Lindstedt and P. Tuomi, Flow experience in game based learning-a systematic literature review. International Journal of Serious Games, 4(1): p. 57-72., 2017. https://doi.org/10.17083/ijsg.v4i1.151

[113] D.J. Burns and L. Neisner, Customer satisfaction in a retail setting: The contribution of emotion. International Journal of Retail \& Distribution Management, 34(1): p. 49-66, 2006. https://doi.org/10.1108/09590550610642819

[114] R.P. Bagozzi, M. Gopinath and P.U. Nyer, The role of emotions in marketing. Journal of the Academy of Marketing Science, 27(2): p. 184-206, 1999. https://doi.org/10.1177/0092070399272005

[115] N.H. Frijda, Moods, emotion episodes, and emotions, p. 381-403, 1993..

[116] J.B. Cohen and C.S. Areni, Affect and consumer behavior. 1991.

[117] N.P. Allan, L.E. Hume, D.M. Allan, A.L. Farrington, and C.J. Lonigan, Relations between inhibitory control and the development of academic skills in preschool and kindergarten: A meta-analysis. Developmental Psychology, 50(10): p. 2368, 2014. https://doi.org/10.1037/a0037493

[118] K. Burgun, Game design theory: A new philosophy for understanding games, CRC Press, 2013:

[119] S. Nicholson, A recipe for meaningful gamification, in Gamification in education and business, Springer. p. 1-20, 2015. https://doi.org/10.1007/978-3-319-10208-5_1 
pag. 26

[120] A. Matallaoui, N. Hanner and R. Zarnekow, Gamification: Using Game Elements in Serious Contexts, S. Stieglitz, et al., Editors. 2016, Springer. p. 3-19.

[121] C. Swan, Gamification: A new way to shape behavior. Communication World, 29(3): p. 1314, 2012.

[122] J. Koivisto and J. Hamari, Demographic differences in perceived benefits from gamification. $\begin{array}{lllll}\text { Computers in Human } & \end{array}$ https://doi.org/10.1016/j.chb.2014.03.007

[123] L. Oaison and S.L. Taalas, The Business of Gamification: A Critical Analysis, M. Dymek and P. Zackariasson, Editors, Routledge. p. 59-81, 2016,

[124] S.S. Shang and K.Y. Lin, An understanding of the impact of gamification on purchase intentions. 2013.

[125] P. Güngör, The relationship between reward management system and employee performance with the mediating role of motivation: A quantitative study on global banks. Procedia-Social and Behavioral Sciences, 24: p. 2011. https://doi.org/10.1016/j.sbspro.2011.09.029

[126] J. Högberg, P. Shams and E. Wästlund, Gamified in-store mobile marketing: The mixed effect of gamified point-of-purchase advertising. Journal of Retailing and Consumer Services, 2018. https://doi.org/10.1016/j.jretconser.2018.07.004

[127] B. Morschheuser, L. Hassan, K. Werder, and J. Hamari, How to design gamification? A method for engineering gamified software. Information and Software Technology, 2017. 